\title{
Repensando Palestina. Una crítica a la paz liberal de Oslo desde un marco analítico del colonialismo
}

\author{
Rethinking Palestine. A critique of the liberal Oslo peace process from an \\ analytical framework of colonialism
}

Lucía LÓPEZ ARIAS

Universidad de Granada

lucia.ugr@gmail.com

Recibido 17/3/2018. Revisado y aprobado para publicación 15/6/2018

\begin{abstract}
Para citar este artículo: Lucía LÓPEZ ARIAS (2018), "Repensando Palestina. Una crítica a la paz liberal de Oslo desde un marco analítico del colonialismo" en Revista de Estudios Internacionales Mediterráneos, 24, $151-172$.
\end{abstract}

Para acceder a este artículo: https://doi.org/10.15366/reim2018.24.009

\section{Resumen}

En este estudio hacemos un análisis crítico del proceso de paz de Oslo iniciado entre palestinos e israelíes en 1993, poniendo de manifiesto cómo estos acuerdos son elementos constitutivos a través de los cuales se manifiestan dos formas de colonialismo que operan y se configuran sobre la tierra de Palestina. Una basada en la lógica de apropiación/violencia, ejercida por Israel; y otra de modernización/desarrollo, ejercida por los donantes internacionales a través de su definición del proceso de paz desde el paradigma de la paz liberal. Se hablará de la narrativa de paz de Oslo, entendido como un marco estructural e ideológico que actúa como una matriz de control que se complementa con estas dos formas de colonialismo llegando a legitimarlas.

Palabras clave: Palestina, paz liberal, colonialismo, Acuerdos de Oslo

\section{Abstract}

In this paper, we conduct a critical analysis of the Oslo peace process which was launched in 1993 by Palestinians and Israelis. Through this analysis, we show that the Oslo Accords are constituent elements that reflect the two forms of colonialism that take form and operate on the land of Palestine. One is based on the logic of appropriation/violence and is exerted by Israel, whereas the other is based on the logic of modernisation/development and is practised by international 
donors, as they define the peace process according to the liberal peace paradigm. We also discuss the narrative of the Oslo peace process, understood as a structural and ideological framework that serves as a control matrix and is complemented by the aforementioned forms of colonialisms, and which eventually manages to legitimize them.

Keywords: Palestine, liberal peace, colonialism, Oslo Accords

\section{Introducción}

Se conoce como "Proceso de Paz de Oslo" a una sucesión de acuerdos alcanzados entre israelíes y palestinos durante la década de 1990 fruto de una serie de negociaciones entre Israel, la Organización para la Liberación de Palestina y algunos Estados árabes para alcanzar un plan de paz integral en Oriente Próximo tras más de treinta años de ocupación. Los acuerdos firmados a lo largo de la década de los noventa, sentarán las bases de las relaciones económicas y políticas entre Israel y los Territorios Palestinos Ocupados hasta el día de hoy. En este artículo queremos hacer un análisis del proceso de Oslo partiendo de la hipótesis de cómo éste ha venido marcado por los presupuestos del paradigma de la paz liberal, sosteniendo las estructuras coloniales de la ocupación militar de Israel sobre los Territorios Palestinos Ocupados.

Para ello partimos del concepto analítico de la paz liberal y de un enfoque de estudio del contexto desde el marco de análisis del colonialismo. El concepto analítico de la paz liberal, procedente de estudios críticos de la paz, nos sirve para describir el marco ideológico que ha guiado las acciones de construcción de paz de los actores internacionales para apoyar el proceso de negociaciones de Oslo entre palestinos e israelíes. Por su parte, el marco de análisis del colonialismo nos orienta tanto a la hora de destacar el carácter colonial de la ocupación, como para poder hacer una crítica de la paz liberal como una forma de colonialidad que se ha ejercido en Palestina, promoviendo los valores liberales occidentales de democratización y de libre comercio al tiempo que se obviaban las estructuras coloniales fundamentales de la ocupación. Desde este marco se pondrá en evidencia las contradicciones inherentes al propio proceso de paz que pueden haber llevado a su fracaso y se recomendarán nuevas alternativas de estudio a la narrativa de la paz liberal de Oslo. Se sugiere una agenda de investigación emancipadora que emplee la perspectiva de análisis del colonialismo de asentamiento para describir las estructuras e ideologías coloniales que caracterizan al movimiento sionista, al tiempo que se visibilizan las resistencias que confrontan la ocupación, la colonización y la opresión como vías para la liberación nacional y que procuran un cambio en el desequilibrio de poder existente entre las partes.

\section{La paz liberal como práctica colonial}

\section{Definiendo la paz liberal. Las democracias liberales no hacen la guerra.}

La tesis de la paz liberal es hoy en día una de las principales versiones de la teoría de las relaciones internacionales enraizada en los principios filosóficos políticos esenciales del liberalismo político, basada en desarrollar la convicción que establece la relación causal entre una estructura política democrática y la ausencia de guerra. Podríamos remontar sus orígenes filosóficos en el ensayo Sobre la paz perpetua publicado por Inmanuel Kant en 1795 quien postulaba que la guerra era 
fruto de la ausencia de Estados republicanos que respeten las libertades, y que el comercio entre las repúblicas permitiría relaciones pacíficas ${ }^{1}$. Quizás es el idealista Woodrow Wilson quien mejor representa los principios del internacionalismo liberal mediante su propuesta de catorce puntos para alcanzar la paz mundial tras la Primera Guerra Mundial en $1918^{2}$. Sin embargo, la principal formulación de la tesis de la paz democrática fue realizada posteriormente por Michael W. Doyle en 1975, estudiando el internacionalismo liberal como fundamento teórico de la construcción de paz y de las implicaciones de esta perspectiva para el análisis de la política internacional y del proyecto de modernización global dentro de los límites, normas, principios e instituciones del liberalismo político. Los Estados liberales, fundados de acuerdo a derechos individuales, la igualdad ante la ley, la libertad de expresión, libertades civiles, el respeto por la propiedad privada y la representación política mediante sistemas democráticos, según la paz democrática, son fundamentalmente pacíficos o contrarios a la guerra. Cuando la ciudadanía, que soporta las cargas de la guerra, es la que elige a sus gobiernos, es menos probable que elija a aquellos gobernantes que involucren al país en una guerra exterior. Además, se entiende que los beneficios del comercio se pueden disfrutar solo bajo condiciones de paz (Doyle, 1975). El objetivo central de su tesis fue reconocer una triple convicción: a) las democracias liberales nunca o casi nunca se hacen la guerra entre sí; b) las democracias liberales no son más propensas a la guerra que los Estados no democráticos, pero tampoco menos; c) aunque las democracias liberales no se hacen la guerra entre ellas, sí han tenido conflictos armados con Estados no liberales. Aunque el análisis de la paz liberal se inicia en la década de 1970, no será hasta la finales del S. XX cuando esta tesis se extendió ampliamente dentro del pensamiento e interpretación de la realidad y la política mundial (Gelardo, 2010).

Con el fin de la Guerra Fría surge una etapa liberal emergente de las relaciones internacionales basada en el consenso de que la democracia, el Estado de derecho, el respeto por los derechos humanos, una sociedad civil activa, y una economía de mercado libre deberían crear una paz sostenible no solo en aquellos Estados y sociedades que se encontraban en una etapa de posconflicto o transicionales, sino como principios universales sobre los que descansaría la posibilidad de alcanzar la quimérica paz mundial. La paz liberal de la posguerra fría reaparece como la superación del debate en las relaciones internacionales entre el idealismo liberal y el realismo, en la que se da una fase de diálogo y confluencia entre estas dos teorías en pos de una agenda común (Salomón, 2002). Con la publicación en 1992 de Una Agenda para la Paz de Boutrus Ghali, en aquel entonces Secretario General de la ONU, se propuso un nuevo marco para gestionar los conflictos armados internacionales. El discurso de la comunidad internacional comenzó a

\footnotetext{
${ }^{1}$ Según Kant el establecimiento de las repúblicas conduce a relaciones pacíficas entre ellas. Los intereses agresivos y egoístas de las monarquías absolutas de antaño son domesticados y los gobiernos republicanos incorporan en su haber el respeto por los derechos individuales y la propiedad privada, mientras que las guerras son consideradas un flagelo para el bienestar de las personas. A diferencia de Schumpeter, las repúblicas de Kant permanecen en un estado de guerra con las no-repúblicas; y a diferencia de Maquiavelo, las repúblicas según Kant son capaces de lograr la paz entre ellas con el objetivo de preservar la democracia y poder disfrutar de derechos internacionales con las repúblicas extranjeras. La Paz perpetua de Kant se alcanzará cuando se acepten de forma generalizada tres artículos definitivos: que la constitución civil de todos los estados debe ser republicana; la ley de las naciones debe estar fundada en una federación de estados libres; la ley de la ciudadanía mundial debe estar limitada a condiciones de una hospitalidad universal.

${ }^{2}$ WILSON, Woodrow, Discurso en la sesión conjunta del Congreso de los EE. UU. sobre las condiciones de paz, Catorce puntos, 8 de enero de 1918, EE.UU.
} 
vincularse con las cuestiones de democracia y buen gobierno, donde el reto de la construcción de paz pasó a incluir además del mantenimiento y consolidación de la paz después de los conflictos, la reconstrucción de sociedades y gobiernos después de la guerra (Paffenholz y Spurk, 2006: 1617). Desde entonces, el supuesto de que la paz liberal se sustenta bajo los componentes esenciales de la democratización y el libre mercado $-y$ en su versión más conservadora, el desarrollo neoliberal- prevalece en infinidad de documentos políticos asociados con la seguridad y la paz mundial ${ }^{3}$.

\section{Los estudios postcoloniales en las relaciones internacionales}

Si bien hay que reconocer que las intervenciones internacionales de apoyo a la paz han ayudado a salvar y mejorar muchas vidas, y han ayudado a prevenir la reaparición de conflictos violentos en algunos lugares, esta forma de construcción de paz liberal también ha tenido resultados inesperados y contraproducentes. Esto ha llevado a que hasta los intervencionistas liberales más ardientes sean conscientes de la posibilidad destructiva que sus operaciones pueden llegar a tener, y de hecho, la paz liberal enfrenta numerosas y diversas resistencias en forma de reacciones locales no conformes con sus intervenciones (Mac Ginty, 2011: 6-7).

A través de diferentes estudios de caso analizados, se revela que muchas comunidades locales son expertas en encontrar maneras de subvertir, esquivar, renegociar y resistir la paz liberal, y cómo la agencia local ha dado lugar a formas de resistencia y a formas híbridas de la paz, a pesar del peso abrumador del proyecto de la paz liberal. Son estudios que muestran en palabras de Oliver Richmond: "una inevitable respuesta postcolonial a las fallas del liberalismo político y a su uso como un patrón universal" (Richmond, 2011: 22). Estas resistencias a la paz liberal son analizadas frecuentemente desde enfoques de los estudios críticos y postcoloniales en las relaciones internacionales que seguimos en este epígrafe.

El campo de investigación que conecta las relaciones internacionales y los estudios postcoloniales tiene sus raíces de pensamiento en diferentes corrientes filosóficas, a menudo ligadas a análisis críticos sobre la modernidad en ciencias sociales y humanas. No representa una doctrina teórica integral, sino un campo heterogéneo de teorías críticas que comparten su compromiso por la descolonización del poder y del saber en un sentido amplio, y que proceden generalmente de aquellos estudios que podríamos denominar como pensamiento no-occidental y/o pensamientos contrahegemónicos en el estudio de las relaciones internacionales (Galindo, 2013). Destacan los marcos teóricos postcoloniales culturales surgidos en las décadas de 1970 y $1980^{4}$, junto con la teoría de la dependencia ligada a análisis de economía política y del desarrollo capitalista desigual $^{5}$. Más recientemente, sobresale la escuela de estudios decoloniales surgida

\footnotetext{
${ }^{3}$ Véase: ONU (1992): Un Programa de Paz (1992); CAD-OCDE (1997): Conflicto, Paz y Cooperación para el Desarrollo en el umbral del Siglo XXI; ONU (2000): Informe del Grupo sobre las Operaciones de Paz de la ONU (2000): Informe Brahimi; ONU (2001): Informe sobre la Prevención del Conflicto Armado (A/55/985); ONU (2003): Resolución Sobre la Prevención del Conflicto Armado 57/337; UE (2003): Una Europa segura en un mundo mejor; ONU (2005): Informe "Un Concepto Más Amplio de Libertad: Desarrollo, Seguridad y Derechos Humanos para Todos; CAD-OCDE (2005): Guidelines on Security System Reform and Governance.

${ }^{4}$ Véase: SAID, W. Edward (1997): Orientalismo, Barcelona, Debolsillo; BHABHA, Homi K. (2003): El lugar de la cultura, Buenos Aires, Manantial; SPIVAK, Gayatri C. (2009): ¿Pueden hablar los subalternos?, Barcelona, MACBA.

${ }^{5}$ Véase: CARDOSO, Fernando H. y FALETTO, Enzo (1969): Dependencia y desarrollo en América Latina, México DF, Siglo XXI; AMIN, Samir (1976): El desarrollo desigual: ensayo sobre las formaciones sociales del capitalismo periférico, Barcelona, Anagrama; WALLERSTEIN, Inmanuel. (1984): El moderno sistema mundial II. El mercantilismo y la consolidación de la economía-mundo europea, 1600-1750, México DF, Siglo XXI.
} 
principalmente de intelectuales latinoamericanos que recalcan cómo el colonialismo, además de todas las dominaciones por las que es conocido, ha sido también una dominación epistemológica, una relación extremadamente desigual del saber-poder que ha conducido a la supresión de muchas formas de saber propias de los pueblos y/o naciones colonizados. A este proceso lo denominan "colonialidad del saber y del poder", siendo esta colonialidad constitutiva de la modernidad y del eurocentrismo (Quijano, 2000; De Sousa Santos y Meneses, 2015).

Teniendo presente esta variedad de enfoques, en términos generales, los estudios postcoloniales en las relaciones internacionales concentran sus análisis en el examen de las relaciones contemporáneas de poder, jerarquía y dominación que se articulan en relación a la experiencia colonial, y que se producen y mantienen por medio de discursos y prácticas que reafirman esas relaciones a nivel global. El debate postcolonial cuestiona la genealogía de la producción del conocimiento científico desde la episteme de la razón moderna, destacando el impacto de las prácticas coloniales sobre la construcción del saber-poder en las relaciones internacionales. Es decir, para los autores postcoloniales las corrientes principales en las relaciones internacionales se basan en la premisa de un entendimiento del poder desde un sujeto occidental excluyente, que privilegia una racionalidad jerárquica y una visión etnocéntrica dominante que mistifica y naturaliza el orden internacional, al tiempo que invisibiliza otras formas de conocimiento y resistencias contra la colonización, tanto locales como globales y que discuten el orden internacional contemporáneo vigente (Chowdhry y Nair, 2002; Galindo, 2013: 88-89). Desde esta perspectiva, lo postcolonial se plantea como una apuesta que confronta el supuesto universalismo de las instituciones modernas, criticando la ausencia de los sujetos subalternos y el silenciamiento de cuestiones como raza, colonialismo e imperialismo en la narrativa dominante de la disciplina, siendo éstos fundamentales en los orígenes de la misma (Fonseca y Jerrems, 2012).

En definitiva, los enfoques críticos postcoloniales de las relaciones internacionales visibilizan mediante su análisis los orígenes coloniales de la disciplina y su carácter profundamente eurocéntrico (Del Arenal, 2014), basado en un conocimiento científico en el que se da una relación de sujeto-objeto entre los intelectuales occidentales y los pueblos colonizados. Se trata pues, de un modelo de conocimiento no reflexivo con el sujeto que analiza y teoriza, lo que ha llevado a la teoría de las relaciones internacionales a naturalizar lo que es social e históricamente construido, como por ejemplo la teoría liberal política, el individualismo o el Estado-nación como entidad básica del sistema mundial, incluso la naturalización del propio orden moderno internacional (Seth, 2011).

\section{3. (De)colonizando la paz liberal}

A inicios de 1990 comienzan a surgir los primeros trabajos teóricos que más que analizar el éxito o fracaso de las operaciones de paz en curso, prestaron atención a los fundamentos conceptuales de la propia construcción de paz o las premisas básicas sobre las cuales las operaciones de paz estaban basadas. Estos análisis provienen principalmente de los estudios críticos de la paz y la seguridad. Más allá de la mera evaluación de la eficacia de las estrategias empleadas, que era generalmente el centro de atención de los análisis de las investigaciones llevadas hasta el momento, comienzan a preguntarse acerca de la naturaleza de la teoría de la paz liberal, así como 
de los marcos ideológicos y/o paradigmas que guiaban las operaciones de construcción de paz que surgieron tras el fin de la Guerra Fría. Un único paradigma, el internacionalismo liberal, parecía guiar el trabajo de la mayoría de las agencias internacionales de construcción de paz internacionales (Paris, 1997: 57). La paz liberal, a pesar de esperar tener un impacto local potencialmente positivo, en muchas ocasiones había fallado a la hora de construir una paz genuinamente liberal o en conseguir la emancipación real de las poblaciones locales sobre las que se intervenía. Buena parte de estos estudios provienen de debates centrados en el paradigma de la construcción de Estados (state-building), los cuales surgen de los estudios críticos sobre la gobernanza mundial y la promoción de gobernabilidad y democracia en sociedades destrozadas por la guerra por medio de la liberalización económica y política. Cuestionan la legitimidad de la paz liberal como una forma de gobernabilidad liberal que actúa como un orden global imperial, o una especie de cosmopolitismo imperialista que da la impresión de ser una nueva forma de neocolonialismo y "misión civilizadora" (París, 2002; Duffield, 2004; Rajagopal, 2005; Richmond, 2006; Newman, et al., 2009; Chandler, 2010; Tadjbakhsh, 2011) $)^{6}$.

Otra fuente teórica fundamental en estas críticas proviene de los estudios decoloniales que se preguntan: ¿Cuál es el legado colonial de los estudios sobre la paz y qué nos puede decir sobre las prácticas y el discurso de la construcción de paz con el que trabajan los países hegemónicos? Utilizando métodos de investigación decoloniales y pedagogía crítica, examinan el legado colonial de la construcción de paz y cuestionan la estructura epistemológica de la paz tal como la conocemos, la practicamos y la enseñamos. Para estos autores el programa de investigación sobre construcción de paz es una "formación discursiva" en el sentido foucaultiano del término, resaltando la relación mutua entre la producción de conocimiento y las relaciones de dominación, tácticas y estrategias de poder. El estatus hegemónico que poseen los enfoques sobre la construcción de paz liberal en las relaciones internacionales es un reflejo de la producción de conocimiento como forma de dominación. Esta hegemonía de la construcción de paz se manifiesta tanto en el plano institucional como en el normativo, así como en el plano intelectual a través de los programas de investigación (Jabri, 2013; Sabaratnam, 2011). Destacan cómo la narrativa de la teoría liberal de la construcción de paz sigue enmarcada en una lógica colonial que está estructurada por una serie de oposiciones binarias con una larga historia en el pensamiento moderno colonial: liberal-iliberal, guerra-paz, moderno-tradicional, desarrollo-subdesarrollo, civilizado-bárbaro. Cuando se llevan a cabo las operaciones de paz internacionales siguiendo los postulados liberales, se espera que sociedades en guerra pasen de un estado iliberal a un ideal liberal cosmopolita. Desde esta premisa, la construcción de paz liberal es un proyecto que no solo está arraigado en el universalismo moral, si no que se manifiesta como una forma de interferencia cosmopolita liberal, la cual "según todos los individuos deben ser tratados como potencialmente modernos, racionales, pacíficas y desarrolladas, sin importar cuáles sean sus historias, tradiciones, normas y valores" (Lidén, 2015: 5-6).

\footnotetext{
${ }^{6}$ En España igualmente surgen estudios recientes que analizan el papel de España en la construcción de la paz y la cooperación internacional para el desarrollo desde enfoques críticos de la seguridad y la paz liberal, véase: RUIZGIMÉNEZ, Itziar (ed.) (2013): El sueño liberal en África Subsahariana. Debate y controversias sobre la construcción de la paz. La Catarata, Madrid; PÉREZ DE ARMIÑO, Karlos; MENDIA AZKUE, Irantzu (eds.) (2013): Seguridad Humana. Aportes críticos al debate teórico y político. Madrid, Tecnos/Hegoa/UPV-EHU; Zirion, IKER (2017): “Críticas al modelo de construcción de "paz liberal» en contextos posconflicto en el África Subsahariana", Iberoamerican Journal of Development Studies, Vol. 6, no 2, pp. 28-47. https://doi.org/10.26754/ojs ried/ijds.242
} 


\section{El paradigma colonial de Oslo}

Siguiendo a Mandy Turner, denominamos "el paradigma de paz de Oslo" tanto a un marco ideológico como otro estructural que se revelan como elementos constitutivos a través de los cuales se manifiestan dos formas de colonialismo que operan y se configuran sobre la tierra de Palestina. Una está basada en la lógica de apropiación/violencia ${ }^{7}$ ejercida por la ocupación y colonización de Israel; y otra, de modernización/desarrollo, ejercida por los donantes internacionales a través de su definición del proceso de paz desde la narrativa de la paz liberal y que orienta la ayuda internacional (Turner, 2012, 2015).

El marco ideológico de Oslo viene marcado por la narrativa de la paz liberal que hemos definido anteriormente. La paz liberal en el proceso de Oslo se muestra como una forma de colonialismo basada en la lógica modernización/desarrollo que promueve unas instituciones democráticas palestinas y una economía de libre mercado al tiempo que obvia la colonización. El marco ideológico de la paz liberal implicó la implementación de una paz colonial favorable a Israel (Turner, 2013: 10) la cual se materializó mediante una serie de normas e instituciones que construyeron lo que denominamos "el marco estructural de Oslo", una matriz de control que se complementa con las técnicas de control israelíes y su lógica de apropiación/violencia. Este marco estructural viene definido por una mayor fragmentación del territorio palestino, la apropiación de los recursos naturales del pueblo palestino por parte de Israel, el mantenimiento de una asimetría de carácter colonial en las relaciones económicas, la construcción de una Autoridad Palestina sin soberanía política y un sistema de financiación de los cuerpos de seguridad de la Autoridad Palestina con el fin de reprimir la resistencia palestina opuesta a las negociaciones de paz (Basallote, Checa, López y Ramos: 2017).

\section{La construcción de una Autoridad Palestina sin soberanía política}

La construcción de Estado de la paz liberal desde el planteamiento de la gobernanza entendida como construcción de soberanía fue aplicada sensu estricto en los Territorios Palestinos Ocupados mediante el proceso de paz con todas sus consecuencias ${ }^{8}$. Se construyó un cuerpo político y gubernamental transitorio al amparo de lo establecido en la Declaración de Principios de 1993, que asumía la creación de una autoridad de gobierno palestino de carácter interino en Gaza y Cisjordania, en el cual los palestinos asumirían gradualmente la administración de los territorios

\footnotetext{
${ }^{7}$ Esta expresión nos remite a la obra de Boaventura de Sousa Santos en la que la lógica de apropiación/violencia es la que opera en los territorios coloniales, la zona del no ser, frente a la lógica de regulación/emancipación propia del pensamiento occidental moderno. Véase: DE SOUSA SANTOS, Boaventura (2010): Para descolonizar Occidente: más allá del pensamiento abismal, Buenos Aires, CLACSO.

${ }^{8}$ La cuestión de Palestina se releva como un caso de análisis particular puesto que no se trababa meramente de reforzar unas instituciones débiles o reconstruir unas estructuras estatales fragmentadas o hundidas a causa de un conflicto bélico interno. En el caso de Palestina no existía un Estado previo -ni todavía existe-, tampoco existían unas estructuras gubernamentales a nivel nacional/estatales propias si descontamos como tal el buró político de la OLP que operaba desde el exilio antes de 1994. Hasta entonces la "gobernabilidad" en Palestina era gestionada por la potencia ocupante a través del Coordinator of Goverment Activities que dirigía la Administración Civil de los Territorios Palestinos Ocupados y era designado por las autoridades israelíes.
} 
de los que Israel se comprometía a irse retirando progresivamente ${ }^{9}$. Este cuerpo político, la Autoridad Palestina, sería legitimado mediante la celebración de elecciones en Gaza y Cisjordania para elegir un Consejo Legislativo Palestino y la transferencia a la Autoridad Palestina de la administración de los temas de educación, sanidad, servicios sociales, cultura, impuestos y turismo. Por otro lado, se estipuló la creación de una fuerza policial palestina para la seguridad interna al tiempo que Israel seguía manteniendo el control de la seguridad de las fronteras externas. No obstante, los problemas fundamentales de la cuestión palestina quedaron aplazadas para el final de las negociaciones, incluyendo el estatus de Jerusalén, la situación de los refugiados palestinos, el asunto de las colonias, el establecimiento de las fronteras definitivas y los acuerdos definitivos en materia de seguridad (Shlaim, 2005: 250-254). Siendo estos los temas más complejos y delicados del conflicto, fueron relegados a una última fase de las negociaciones y hasta el día de hoy siguen sin ser resueltos ${ }^{10}$.

Aunque la construcción de la Autoridad Palestina era considerada de importancia capital como base de las estructuras de gobierno del futuro Estado de Palestina, lo cierto es que durante la primera etapa interina de los Acuerdos de Oslo, la dimensión institucional y gubernamental del desarrollo de Palestina fue relegada a un segundo plano frente a la asistencia técnica para el crecimiento económico y la promoción del sector privado (Sayigh y Shikaki, 1999). Desde la firma de la Declaración de Principios de 1993, los Territorios Palestinos Ocupados quedaron subordinados a las prescripciones de las instituciones donantes internacionales, cuyas recomendaciones afectaron profundamente a la economía y política de la Autoridad Palestina. Mientras los EE. UU. guiaban políticamente las negociaciones de paz, el Banco Mundial fue el encargado de gestionar el programa marco que guiaría el desarrollo económco de los Territorios Palestinos Ocupados y la ayuda internacional para tal fin. El Programa de Asistencia Urgente del Banco Mundial de 1994 que marcó las directrices de la ayuda internacional durante la década de 1990, ponía de relieve la necesidad de mejorar la capacidad institucional de las autoridades gubernamentales que iban a ser recién creadas. No obstante, el posterior apoyo a los aspectos político-institucionales del desarrollo de Palestina y la democratización de las instituciones palestinas, terminó siendo marginal. Por otro lado, las consecuencias destructivas que han traído consigo las restricciones de soberanía de la Autoridad Palestina en todas las esferas, política, económica y de seguridad en su propio territorio, llevaron a un aumento del descontento de la población palestina, a la pérdida de legitimidad de la propia Autoridad Palestina, y a un desgaste de la confianza en los Acuerdos de Oslo, que vino acompañado de un aumento del apoyo hacia grupos de resistencia armados contrarios a los mismos, aspectos que explican en gran medida el estallido de la Segunda Intifada en el año 2000.

\footnotetext{
${ }^{9}$ Según la división territorial de los Acuerdos de Oslo en zonas A, B y C, la Autoridad Palestina tomaría el control sobre la seguridad exclusivamente en el área $A$, así como todas aquellas competencias referentes a la administración civil de la población. En el área $B$ sólo tendría autoridad en la gestión administrativa civil, quedando el control del territorio bajo administración israelí. El resto del territorio, el área $\mathrm{C}$, quedaría bajo total control de Israel en cuestiones civiles y de seguridad, quedando la administración civil de la población bajo órdenes militares. Esto significó que en la práctica la Autoridad Palestina sólo tenía jurisdicción civil y territorial sobre el 17,2\% de los Territorios Palestinos Ocupados. Para más información ver: PASSIA (2010): Area C, The Key to the Two-State Solution, Jerusalén, PASSIA. Disponible en: http://www.passia.org/publications/bulletins/area-c/area-c.pdf

10 En la Declaración de Principios se tomaron en consideración las resoluciones 242 y 338 de la ONU, pero sin embargo se omitieron las resoluciones 181 de 1947 que estipulaba el plan de partición de Palestina y la internacionalización de Jerusalén así como la 194 de 1948, relativa al derecho al retorno y compensación de los refugiados palestinos.
} 
En el año 2003 se presentó un nuevo plan de paz comúnmente conocido como la Hoja de Ruta. En este nuevo plan, las exigencias al pueblo palestino eran claras: constituir un gobierno democrático y establecer unas fuerzas de seguridad que reprimiesen la resistencia armada surgida durante la Segunda Intifada y con las que Israel estuviese conforme. Estas mismas sirvieron para aplacar la oposición palestina interna crítica con la propia Autoridad Palestina (Reinhart y Ahronoth 2003). Sin embargo, el plan de la Hoja de Ruta no prestó de nuevo atención a la ocupación israelí de Cisjordania, Gaza y Jerusalén Oriental, ni a las colonias israelíes, y simplemente exigió a Israel su paralización pero sin dejar del todo definida la cuestión territorial de su retirada. En su lugar, puso la atención en cuestiones de la política interna de Palestina y en cómo combatir la violencia palestina (Khalidi, 2003). Al igual que en los Acuerdos de Oslo de 1993, se aplazaban para las negociaciones finales las cuestiones esenciales del proceso colonial sionista de Palestina. Esto ha permitido que Israel pudiese seguir con su estrategia dilatoria mientras continuaba profundizando la colonización (Abu-Tarbush, 2009, 2013).

La Hoja de Ruta fracasó tras las elecciones de 2006 influyendo directamente en el "nuevo proceso de paz", en la política interna palestina, así como en la ayuda internacional. La lista política "Cambio y Reforma" que representaba a Hamás, gana las elcciones al Consejo Legislativo Palestino. Estos resultados electorales no son reconocidos ni por Fatah -en el poder de la Autoridad Palestina y la OLP hasta el momento-, ni por la comunidad internacional que apuntala en el poder a Mahmoud Abbas, quien había ganado las elecciones presidenciales en 2005, pero no así las parlamentarias de 2006. Inmediatamente se produce una fractura interna en el gobierno de Palestina que lleva a una división de unidad nacional que dura hasta el día de hoy, a pesar de la firma en 2014 del débil Acuerdo de Doha de reconciliación nacioal. Es importante resaltar el bloqueo financiero que ejercierom los donantes al ejecutivo de Hamás de la Autoridad Palestina, y la creación de un sistema de financiación paralelo con el fin de poder distribuir los fondos necesarios sin recurrir a los canales habituales que pasaban por el control de los Ministerios palestinos. Aunque este Mecanismo Internacional Temporal (TIM por sus siglas en inglés) evitó inicialmente el colapso financiero de la Autoridad Palestina, el bloqueo provocó una gran disminución de la disponibilidad de recursos, que resultó en una implosión gradual de sus instituciones debido a la incapacidad del pago de salarios de sus funcionarios, privación de servicios civiles e incapacidad para prestar servicios básicos a la población. La pérdida de transparencia y rendición de cuentas volvió a ser especialmente flagrante, causando un retroceso tras años destinados a fortalecer las capacidades democráticas y de buen gobierno (Nashashibi, 2007). Posteriormente, todo esfuerzo por impulsar el proceso de negociaciones se vio de nuevo abocado al fracaso con la fractura política interna palestina de 2007, en la que Hamás tomó el poder en la Franja de Gaza tras enfrentamientos armados con las fuerzas de seguridad de la Autoridad Palestina, situación en gran medida provocada tras el rechazo de la comunidad Internacional de los resultados de las elecciones de 2006, y que terminó en lo que algunos han calificado como "guerra civil", Ilegando a la insólita situación en la que "emergen" una suerte de dos gobiernos, uno en Gaza otro en Cisjordania, pero en ausencia de Estado (Álvarez-Ossorio, 2007).

En un contexto de absoluta división del movimiento nacional, con la mayoría de los integrantes del Consejo Legislativo Palestino encarcelados por Israel - haciéndolo de facto inoperante- y con el mandato de la presidencia palestina técnicamente expirado desde 2009; la Autoridad Palestina 
hizo un nuevo esfuerzo por aumentar su legitimidad ante el pueblo palestino - pero especialmente ante la comunidad internacional-, lanzando en 2008 el Plan Palestino de Reforma y Desarrollo (PRDP por sus siglas en inglés) diseñado y dirigido por Salam Fayad, el entonces Primer ministro de la Autoridad Palestina"11. Bajo los parámetros del denominado "paradigma fayadista", la Autoridad Palestina, con el apoyo de la comunidad de donantes, procuraba la construcción del Estado palestino a través de cuatro pilares: la reforma del sector de seguridad y la aplicación del Estado de derecho; la construcción de instituciones de la Autoridad Palestina responsables políticamente; la prestación efectiva de servicios públicos; y el crecimiento económico liderado por el sector privado en una economía de libre mercado. A través de la implementación de estas políticas, surgiría una "nueva" Cisjordania y la Autoridad Palestina se transformaría en un Estado funcional (Tartir, 2015: 480-481). Alaa Tartir admite que el "fayadismo" como paradigma ha sido tan criticado como aplaudido. Algunos han celebrado las reformas de Fayad y argumentan que una mejor gestión y transparencia de la Autoridad Palestina ha favorecido la consolidación de la paz y el desarrollo de Palestina. Mientras, otras voces se oponen al modelo del programa de Salam Fayad por profundizar el proceso de neoliberalismo económico como estrategia para alcanzar la paz y el Estado de Palestina. Según sus críticos, el "fayadismo" no fue tan bien recibido por el conjunto de la sociedad palestina como por la comunidad internacional, la cual le ofreció un creciente respaldo tanto político como mediático. Entre la sociedad palestina crítica, el plan de reforma y desarrollo de Salam Fayad, fue visto como un programa que ofrecía desarrollo, crecimiento y prosperidad pero de nuevo sin ninguna estrategia de resistencia o desafío a la ocupación y colonialismo de Israel. Se basaba en una propuesta que pretendía construir el Estado de Palestina a través de la creación de instituciones económicas neoliberales, redefiniendo la lucha nacional palestina desde estas (Khalidi y Samour., 2011). Es decir, seguía conservando la asimetría de poder entre Palestina e Israel, la dependencia económica de Palestina tanto de Israel como de la comunidad Internacional, así como la lógica de la primacía de la seguridad de Israel y la continuación de su política expansionista (Leech, 2012). Hasta la actualidad, todos los esfuerzos para la construcción de un Estado democrático palestino se han visto afectados por la realidad política de la ocupación israelí, la profunda crisis fiscal y la división entre la Cisjordania dominada por Fatah y la Franja de Gaza controlada por Hamas. Aunque se programaron elecciones presidenciales y legislativas para el año 2010, estas fueron suspendidas por falta de unidad nacional. Además, la constante inestabilidad política y crisis financieras, combinada con una tensa situación de la seguridad, interrumpen cualquier plan de reforma del sector público y en los últimos años se han logrado escasos progresos en la reforma de los sectores de justicia y seguridad (Comisión Europea, 2014).

En este somero recorrido que acabamos de hacer por el proceso de paz y sus planes de construcción del Estado palestino, podemos destacar cómo se creó una entidad a la que los propios Acuerdos de Oslo impusieron drásticas limitaciones de soberanía. En este sentido, previo al reconocimiento de la soberanía del Estado de Palestina, la población de Palestina se vio obligada a emprender toda una serie de reformas políticas y económicas orientadas desde el exterior de acuerdo a los parámetros establecidos por el proceso de la paz liberal, sin tener por ello la seguridad de que la ocupación y la colonización se terminaría. El diseño del proceso de las negociaciones de paz de Oslo, desde su inicio, implicó mantener de facto la estructura económica

\footnotetext{
${ }^{11}$ Las bases de la política económica y política de Salam Fayad desde que fue nombrado Primer Ministro en el año 2007 hasta 2013, está recogida en tres documentos: AUTORIDAD NACIONAL PALESTINA (2008): Plan Palestino de Reforma y Desarrollo (2008-2011), Ramala; AUTORIDAD NACIONAL PALESTINA (2009): Palestina: Poner Fin a la Ocupación. Establecer un Estado. Programa del Decimotercer Gobierno, Ramala; AUTORIDAD NACIONAL PALESTINA (2009): Última fase hacia la libertad. Segundo Año del Programa del Decimotercer Gobierno, Ramala.
} 
y la política colonial israelí. El fracaso de los acuerdos se debió en realidad a la propia naturaleza descompensada del esquema negociador caracterizado por el bilateralismo asimétrico, no reciprocidad, gradualidad, ambigüedad, falta de mediación parcial externa y ausencia de garantías (Barreñada, 2008; Izquierdo y Álvarez-Ossorio 2007).

El dilema principal ha sido que la Autoridad Palestina no ha sido construida tanto para promover la democracia y un Estado independiente en Palestina como para gestionar la ayuda internacional y garantizar la seguridad de Israel (Friedrich y Luethold, 2007; Bouris, 2012). Además, la arquitectura institucional establecida por medio de los Acuerdos de Oslo, basada esencialmente en la insistencia de priorizar la seguridad de Israel, estableció una asimetría de control entre Israel y la Autoridad Palestina que ha sido la responsable en varios aspectos del fracaso de la gobernabilidad de la Autoridad Palestina y el de las propias negociaciones de paz (Khan, 2004). Mientras la población local entiende la construcción de Estado como el fin de la colonización y el reconocimiento de su autodeterminación, para los promotores del proceso de Oslo significa la promoción de capacidades institucionales que garanticen la seguridad de Israel y del sector privado con el fin de conseguir la estabilidad económica regional (Nagarajan, 2014).

\section{Mantenimiento de una economía colonial asimétrica. La paz económica}

Del mismo modo que los Acuerdos de Oslo no estuvieron diseñados para promover un Estado democrático independiente en Palestina, tampoco lo fueron para promover una economía palestina independiente. La Autoridad Palestina nació con una falta de control sobre los recursos económicos más importantes, debido al control físico de Israel sobre todos los puntos de entrada y salida del territorio palestino, y el cobro de impuestos aduaneros que han influido en la entrada de capitales en la Autoridad Palestina, vulnerable a fluctuaciones derivadas de la inestabilidad política y de seguridad con Israel. Por otro lado, las restricciones al movimiento de las mercancías y de los propios palestinos entre Cisjordania, Gaza y Jerusalén Este, que es un importante centro de la actividad cultural, social y comercial de Palestina, hicieron inviable la posibilidad de una Palestina unificada territorial y económicamente.

La noción de la paz económica presente en los Acuerdos de Oslo no era nueva en el discurso de la política israelí hacia los territorios palestinos. Ya en las décadas de 1960 y 1970 se pensaba en cómo la ocupación favorecería la unificación económica; así por ejemplo, la política del Ministro de Defensa israelí Moshe Dayan, tras la Guerra de los Seis Días, proponía promover el "desarrollo económico" de los territorios ocupados mediante una política económica de "puentes abiertos" con la esperanza de que, mejorando las condiciones de vida del pueblo palestino, este abandonaría las reivindicaciones de sus derechos políticos. La propuesta de Simón Peres de 1993 del "Nuevo Oriente Medio", que orientará la paz liberal de los Acuerdos de Oslo, formulaba la idea de que la integración económica de Israel en Oriente Medio traería paz y el desarrollo para toda la región. Cuando Simón Peres planificó su programa de paz, describió la idea central de un nuevo sistema de integración económica de Israel en Oriente Medio, mediante la creación de una zona regional de libre comercio que permitiría a Israel invertir su capital (Peres, 1993). Desde entonces, la intergración económica ha seguido siendo un elemento significativo para el mantenimiento sostenible de la ocupación; de hecho, constituyó un elemento clave del Protocolo de París de 1994 -la adenda económica a los Acuerdos de Oslo- estableciendo los cimientos de las relaciones 
económicas existentes hoy en día entre Israel y los Territorios Palestinos Ocupados, combinando desarrollo económco con el supuesto proceso de paz (IKV Pax Christi, 2012).

El interés de la política israelí por una paz económica con Palestina radica en tres aspectos clave. En primer lugar, la institucionalización del mantenimiento de la dependencia económica de los Territorios Palestinos Ocupados de la economía israelí por medio del Protocolo de París de 1994; en segundo lugar, la integración económica y normalización de Israel en la región de Oriente Medio con el fin del boicot que ejercían los países árabes; por último, la "incrustación" de la economía israelí y palestina en el proceso de globalización, mediante la promoción de la inversión extranjera, que dio origen a una élite neoliberal palestina e israelí que se benefició de los dividendos de la paz (Nitzan y Bichler, 1996, 2002; Peled, 2004).

La gestión de Israel sobre Cisjordania y Gaza ha sido colonial en la medida en que expropió tierras palestinas y desarticuló la economía palestina, haciéndola totalmente dependiente y cautiva de la economía israelí, incluso después de Oslo. Los Acuerdos de Oslo redefinieron, en lugar de eliminar, la economía de la ocupación y el colonialismo, y convirtieron el concepto de seguridad israelí - y no la ocupación ilegal- en el elemento definitorio de la vida política y económica palestina. El Protocolo de París determinó el crecimiento de la economía palestina a las consideraciones militares y territoriales israelíes. Como resultado, la responsabilidad asignada a la Autoridad Palestina para la gestión de su economía fue limitada en su jurisdicción territorial, gestión de aranceles, control de la movilidad laboral y de mercancías, así como en la exportación e importación de productos (Farsakh, 2008: 6-9). A pesar de que los Acuerdos de Oslo ofrecieron plena administración a la Autoridad Palestina sobre algunos territorios (zona A), las directrices de la política económica palestina siguieron en manos de Israel. El Protocolo de París otorgó poderes limitados a la Autoridad Palestina sobre su política económica e ignoró la cuestión de la soberanía del pueblo palestino sobre el uso de su tierra y sus recursos naturales, lo que implicó numerosas limitaciones a la hora de poder planificar sus propias estrategias de desarrollo, especialmente en la agricultura, sector prioritario en la economía palestina (Samara, 2000). De hecho, no creó un área de libre comercio propiamente dicha, sino una unión aduanera en la que la política comercial de Israel se impone a la palestina y no tiene en cuenta las diferencias entre ambas economías. La preferencia de una unión aduanera está vinculada con el hecho de que no requiere la delimitación de fronteras. Esto ha permitido a Israel mantener las fronteras provisionales mientras sigue expropiando tierras, construyendo el muro de separación desde el año 2002 y aumentando el número de colonias en territorios ocupados. Los productos israelíes entran y son vendidos en los Territorios Palestinos Ocupados sin prácticamente ninguna restricción, en cambio, se imponen severas limitaciones al movimiento de productos palestinos entre los Territorios Palestinos Ocupados e Israel, así como dentro de los Territorios Palestinos Ocupados, desconectando económicamente Gaza de Cisjordania, y a su vez, Jerusalén de ambas (Arafeh, 2017, 2018). Por otro lado, uno de los aspectos más destacados en estas relaciones económicas desiguales, es el control que tiene Israel sobre la recaudación del cobro y retención de los ingresos procedentes de los impuestos aduaneros de los Territorios Palestinos Ocupados, que luego son transferidos a la Autoridad Palestina. Los ingresos aduaneros se convirtieron en una de las principales medidas que restringen el ámbito de acción de la Autoridad Palestina y una herramienta de presión política que es empleada por Israel mediante la amenaza de no realizar la transferencia de lo recaudado.

En esencia, el Protocolo de París no implicó ningún cambio sustancial en la política de dependencia económica asimétrica y colonial que venía manteniendo la ocupación; y ha sido reiteradamente empleado por Israel con el objetivo de ajustar la economía de la ocupación a sus 
intereses, necesidades y estructura económica, en detrimento de la economía y el desarrollo de Palestina. Este proceso forzó a todas las clases sociales palestinas a tener que interactuar de forma directa con la economía israelí reforzando de este modo la dependencia y debilidad económica de Palestina, siendo el sector privado el motor de esta estrategia de desarrollo (UNCTAD/GDS/APP, 2006). Cabe mencionar también, que los Acuerdos de Oslo y el Protocolo de París normalizaron las relaciones económicas coloniales que venía manteniendo Israel. La normalización económica se manifiesta a través de proyectos conjuntos palestino-israelíes ${ }^{12}$ que ayudan a la potencia ocupante a beneficiarse e infiltrar aún más sus estructuras en los territorios ocupados, representando un serio obstáculo para la liberación nacional palestina (Dana, 2014).

\section{La negación del carácter colonial y la visión del conflicto}

El paradigma de la paz liberal de Oslo implicó considerar que Palestina e Israel habían entrado en una etapa de posconflicto, lo que tuvo una repercusión enorme en el enfoque de construcción de paz desde el que se trabajó, tanto en un nivel conceptual como de procedimiento. Esta preconcepción condujo a que se tendiesen a omitir las causas profundas de naturaleza colonial del conflicto, manteniendo una visión de construcción de paz basada en la creación de instituciones gubernamentales palestinas, al tiempo que se promovía una economía de libre mercado bajo un régimen de ocupación y colonización que en realidad nunca cesó de consolidarse. El apoyo desde el exterior para la construcción de paz y de desarrollo no solo obvió las causas de carácter colonial de la ocupación, sino que llegó a legitimarlas, incluso por momentos a complementarse con ellas, tal como acabamos de ver.

Durante décadas, desde las instituciones internacionales encargadas de salvaguardar el respeto por los derechos humanos, se ha tratado la cuestión palestina-israelí como un caso de ocupación beligerante, algo que es incuestionable, no obstante, este ha sido un enfoque que asume que la legislación internacional relevante para el análisis de la situación de los Territorios Palestinos Ocupados es el Derecho Internacional Humanitario, que establece las normas en tiempos de guerra. Desde el planteamiento de la ocupación, los juristas y movimientos de solidaridad internacional se dedicaron a registrar minuciosamente las violaciones del Derecho Internacional Humanitario que Israel incumplía, dando lugar a innumerables, por momentos inabarcables, informes, estudios y resoluciones de la ONU que se han ido quedando en papel mojado (Tilley, 2012).

Pero la narrativa de la ocupación beligerante, siendo técnicamente correcta, ha introducido una debilidad analítica, el error de encubrir el reconocimiento de que la ocupación israelí también implica crímenes contra la humanidad como el colonialismo y el apartheid ( $\mathrm{CISCH}, 2009$; ESCWA, 2017). El paradigma dominante de la ocupación se tradujo en un consenso internacional que adoptó la interpretación de "dos pueblos en una tierra" institucionalizada en la solución de los dos estados de los Acuerdos de Oslo. Los supuestos desde el paradigma de la ocupación, han sido que entre Israel y Palestina había un conflicto entre dos pueblos y/o naciones, en el cual una de las

\footnotetext{
12 Proyectos como las zonas industriales conjuntas, los foros comerciales israelo-palestinos, las inversiones palestinas en Israel y en sus colonias, y la gestión común de los recursos hídricos.
} 
partes ocupaba parte del territorio de la otra, y las narrativas incompatibles de ambos pueblos implicaban escalas de violencia de ataque y contraataque que solían llevar a un círculo vicioso de violencia de unos contra otros, en las que ambas partes tenían igual grado de responsabilidad ${ }^{13}$. Así pues, la fórmula para la solución fue la denominada "paz por territorios", en la que Israel se retiraría gradualmente de los Territorios Palestinos Ocupados, siempre y cuando el pueblo palestino garantizase la seguridad de Israel renunciando a su resistencia (Tilley, 2012).

El discurso dominante internacional sigue describiendo a Israel como una democracia (algunos incluso como un Estado democrático judío), y rara vez como un Estado colonial que impone a los palestinos un sistema que combina características de apartheid. Desde este discurso, se sostiene un consenso internacional que sigue manteniendo los siguientes mitos: que se puede actuar bajo el marco de interpretación de la situación como posconflicto; que el desarrollo puede alcanzarse bajo una situación de ocupación; que existe una economía palestina independiente; y que el Estado de Palestina puede alcanzarse mediante soluciones meramente técnicas como promover unas instituciones democráticas y transparentes pero bajo un sistema de ocupación, es decir, la ilusión de que los palestinos pueden gestionar un Estado bajo las condiciones de colonialismo existentes sobre el terreno. En definitiva se sigue manteniendo el mito de la posibilidad de la solución de los dos Estados, a pesar de los reiterados fracasos a lo largo de las últimas dos décadas en las negociaciones bilaterales entre Palestina e Israel, bajo el auspicio de los EE. UU., las cuales han permitido la transformación demográfica, geográfica y económica de los Territorios Palestinos Ocupados llevada a cabo por una "colonización de asentamientos" (Hilal, 2015: 3-4).

A la luz del estancamiento de las negociaciones entre Israel y Palestina, y de la completa falta de perspectivas políticas para el pueblo palestino, el cuestionamiento de los Acuerdos de Oslo cada vez está más presente entre la sociedad palestina. En los últimos años se han hecho repetidos llamamientos para declarar el fin del proceso de Oslo e incluso la posibilidad de disolución de la propia Autoridad Palestina con todas las implicaciones que conllevaría ${ }^{14}$. Es evidente que nos encontramos lejos de poder alcanzar una paz justa y duradera a través de las negociaciones, y hasta podría resultar obstinado pensar que la solución de los dos Estados resulta la única opción viable. Históricamente han existido propuestas alternativas de paz, siendo quizás la más conocida la que formula una solución fundamentada en la creación de un único Estado binacional, en el que la ciudadanía, y no una comunidad étnica, sería el punto de partida para elaborar una constitución genuinamente democrática y laica que asegurase igualdad de responsabilidades y derechos a toda su ciudadanía, independientemente de su origen étnico o religioso. La idea de un único Estado se remonta incluso antes del Plan de la ONU para la partición de Palestina de 1947. Igualmente, los orígenes del movimiento de liberación nacional palestino también dieron testimonio de esta opción ${ }^{15}$. Desde entonces, la propuesta sigue vigente y ha sido reivindicada a lo largo de los años por diferentes intelectuales y movimientos de solidaridad con Palestina.

\footnotetext{
${ }^{13}$ Los movimientos de solidaridad internacional denominan a esta visión como equidistancia, es decir, una noción que reconoce la existencia de un equilibrio entre las partes.

${ }^{14}$ Para saber más sobre las implicaciones de la disolución de la AP ver los informes de "One Day After" elaborados por el Palestinian Center for Policy and Survey Research en el año 2013, en colaboración con el U.S./Middle East Project (US MEP) y el Norwegian Peacebuilding Resource Centre (NOREF). Todos los informes están disponibles en: http://www.pcpsr.org/en/node/104

${ }^{15}$ Ver: BUBER, Martin; MAGNES, J. Leon y SMILANSKY, Moshe (1946): Palestine, a bi-national State, Jerusalén, Ihud; PALESTINE NATIONAL LIBERATION MOVEMENT (1970): Towards a democratic state in Palestine for Moslems, Christians and Jews, 2th World Conference on Palestine, Ammán.
} 
López Arias, Repensando Palestina...

\section{Repensar Palestina. Hacia una agenda de investigación descolonizadora}

La narrativa de paz de Oslo sigue vigente hasta el momento a pesar de su evidenciado fracaso, y no se ha reformulado a pesar de surgir cada vez más voces críticas hacia el mismo, tanto dentro como fuera de Palestina. En los últimos años estamos presenciando el surgimiento de nuevas historiografías y perspectivas que enfatizan la relevancia de hacer uso de una analítica colonial para estudiar la ocupación de Palestina y el movimiento sionista que la sustenta. Esta nueva mirada pretende "ir más allá" de la narrativa que define la historia política de Palestina en términos de conflicto, basada en el análisis de cómo establecer mediante negociaciones algún tipo de Estado palestino que conviva pacíficamente con el Estado de Israel. Comprender a Israel como un Estado colonial nos ayuda a cuestionar la narrativa de Oslo de resolución de conflictos y diálogo entre dos partes iguales, para avanzar en un análisis serio de las continuidades estructurales del sionismo y la ideología que guía las políticas y prácticas israelíes hacia los palestinos tanto en los Territorios Palestinos Ocupados como en el propio Estado de Israel. Igualmente, sirve como un medio para oponerse a la fragmentación de la tierra, la población y la economía palestina producidos por este proyecto. Salir del impase en el que se encuentran las negociaciones de Oslo requiere un compromiso con el proceso de descolonización de Palestina, nuevos marcos y nuevos presupuestos para entender por qué el conflicto persiste. Solo por medio del fin de la ocupación y la eliminación de las estructuras de opresión que crean el apartheid y el colonialismo israelí existentes sobre el terreno, podremos discutir sobre una solución futura a largo plazo (Tartir, 2015).

El análisis del colonialismo para explicar lo que sucede en Palestina no es nuevo. Hubo un tiempo en el que sirvió como elemento ideológico principal para el movimiento político palestino, que abordó la cuestión de la descolonización a través de la lente anticolonial de liberación nacional. Igualmente, el trabajo intelectual de muchos escritores, académicos y activistas, principalmente de la izquierda política, ha concentrado su análisis en el sionismo como un movimiento colonial conectado con el imperialismo europeo con el que se dio una colaboración mutua (Rodinson, 1973; Shafir, 1989; Masalha, 2012; Golan, 2011). Aunque el marco de análisis del colonialismo nunca se ha abandonado del todo, perdió fuerza a partir de los Acuerdos de Oslo. No obstante, recientemente se ha recuperado junto con el auge del campo de estudios del colonialismo de asentamiento de la última década a raíz de la obra de Patrick Wolfe. La obra de Wolfe aportó una descripción teórica de las estructuras que caracterizan el colonialismo de asentamiento, a partir de la cual ha permitió el surgimiento de numerosos estudios de caso comparativos que han profundizado en el conocimiento de este campo de estudio ${ }^{16}$. Su idea principal ha sido resumida en numerosas ocasiones mediante su expresión: "los colonos vienen para quedarse, el colonialismo de asentamiento es una estructura, no un evento". Este planteamiento condensa su explicación del proceso de construcción social y política del modo específico del colonialismo de asentamiento, donde la eliminación del otro y el acceso al territorio es el principio organizativo de la sociedad colonial. Es decir, la lógica de la eliminación es inherente al colonialismo de

\footnotetext{
${ }^{16}$ Para ver más sobre estudios de colonialismo de asentamiento: PEDERSEN, Susan y ELKINS, Caroline (ed.) (2005): Settler Colonialism in the Twentieth Century, Londres, Routledge; VERACINI, Lorenzo (2010): Settler Colonialism: $A$ Theoretical Overview, Hampshire, Palgrave MacMillan.
} 
asentamiento, y el motivo principal para la eliminación no es tanto la raza, la religión, la etnia o el grado de civilización - aunque estén presentes - sino el acceso al territorio, siendo la territorialidad un elemento irreductible de esta forma de colonialismo (Wolfe, 2006). El propio Wolfe describe en su análisis al sionismo como una forma de colonialismo de asentamiento. Simultáneamente comienzan a surgir estudios comparativos del movimiento sionista con otras formas de colonialismo como fueron los casos de Sudáfrica, la antigua Rodesia, o casos como los de Australia, Canadá y EE. UU. (Collins, 2011; Krebs y Olwan, 2012; Veracini, 2013; Piterberg, 2015; De Jong, 2017). Estos análisis se concentran en describir las estructuras y la ideología que impulsaron el movimiento sionista, resaltando la primacía en la apropiación de la tierra y la limpieza étnica como piedra angular para comprender este movimiento.

El primer Congreso Sionista que tuvo lugar en Basilea en el año 1897, caracterizó a Palestina como una tierra sin pueblo. Esta idea de definir Palestina como una terra nullius que sostuvo el sionismo es una cuestión fundamental para comprender el carácter colonial de este proyecto político desde su origen, y la incompatibilidad de su éxito con la existencia de población nativa en la tierra de Palestina. A diferencia de otros casos de colonialismo, para el sionismo, la apropiación y control de la máxima cantidad de tierra, así como la eliminación de la población nativa que la habitaba, han estado presentes en su discurso político desde el inicio y se han mantenido con la creación del Estado de Israel. Cuando se pretende analizar el sionismo como una forma de colonialismo, nos encontramos con que el debate se complejiza si lo que se pretende es analizar los marcos ideológicos y las estructuras propias del modo de colonialismo que caracterizan el movimiento sionista. Según la narrativa sionista - y la comunidad internacional que la apoyó- el sionismo es un movimiento justo de liberación nacional que llevó la modernización y el progreso a una Palestina primitiva. No obstante, destacados autores como llan Pappé defienden que el sionismo es una forma no convencional de colonialismo que se diluye en unas características nacionales fuertes. Aunque el sionismo piensa por un estímulo nacionalista, actúa como un colonialismo, siendo la tierra un asunto central. Es decir, la territorialización del discurso sionista es lo que transformó al sionismo de un proyecto nacional a un proyecto colonial (Pappé, 2008). Dicho de otro modo, la colonización tuvo que ser el instrumento estructural de construcción nacional, no la consecuencia de un movimiento de liberación nacional (Sayegh, 1965: 2). Así, desde la perspectiva analítica de Wolfe que acabamos de resumir, podemos considerar que el sionismo no es un evento (i.e. la guerra de 1948), el sionismo es una estructura, y es una estructura colonizadora de asentamiento, lo fue a finales del S XIX, y lo sigue siendo a día de hoy. Además, en muchos sentidos, el discurso sionista sobre Palestina es orientalista y a la vez colonialista. En la idea de que Israel es un Estado europeizado, occidentalizado y democrático, se perfila una colonialidad inherente vinculada a la idea del sionismo como forma de modernización y desarrollo, en oposición al indígena hostil que es representada generalmente mediante la retórica del terrorismo palestino (Pappé, 2014).

Trabajar desde un marco de interpretación colonial como alternativa al proyecto dominante de la paz liberal tiene importantes implicaciones contrahegemónicas para reformular Israel-Palestina y para proponer alternativas al proceso de Oslo, quebrantando ambas lógicas de apropiación/violencia y de modernización/desarrollo que construyó. Desde esta perspectiva, cuestionar el paradigma dominante de la paz liberal que ha guiado el Proceso de Oslo, significa también preguntarse si buscamos una paz que sea modelada según el contexto del colonialismo, o según las prácticas y formas de conocimiento alternativas y saberes locales. Oponerse al proceso de Oslo no significa estar en contra de la paz. Más bien se trata de proponer el reto de cómo emprender un análisis de los proyectos de construcción de paz que atienda a las prácticas 
micropolíticas cotidianas del colonialismo y a las estructuras económicas y políticas globales, así como al modo en que ambas se relacionan manifestándose en la vida cotidiana de la resistencia local palestina. En este caso, implica explorar cómo la lucha de liberación palestina, a lo largo de su historia de resistencias, ha propuesto sus propias nociones alternativas de paz al paradigma hegemónico. Estas propuestas, considerando el carácter colonial del conflicto, afirman que no es posible resolverlo simplemente promocionando una gobernanza de la Autoridad Palestina con el objetivo de que sea un "interlocutor válido para la paz" según las exigencias de Israel, o el modelo económico liberal que se promovió desde el exterior. Lo que proponen es que se hagan ofertas de paz que atiendan a las injusticias básicas y la opresión que provoca una dominación colonial como la ocupación israelí.

Para avanzar y crear una agenda de investigación liberadora y transformadora, es necesario analizar la estructura que sustenta las tácticas coloniales de Israel. No obstante, este marco de análisis no debe quedarse en la "pura teoría" y de bebe servir para proponer alternativas políticas (Busbridge, 2017: 15). Además, esta perspectiva ofrece una poderosa herramienta política y teórica para reorientar y crear alianzas y convergencias de solidaridad con otras luchas en circunstancias de colonialismo y racismo similares, recuperando por otro lado, la propia historia de internacionalismo anticolonial que caracterizó el movimiento nacional palestino en anteriores décadas (Jabary et al., 2012). Puesto que la particularidad del colonialismo de asentamiento es subrayar la eliminación del otro, una de las prioridades en la forma de resistirlo es mediante la permanencia de los nativos y destacar la importancia de la centralidad de la tierra y la memoria para un proyecto emancipador (Tabar, Desai, 2017). Iniciativas que recuperan la narrativa de la historia palestina y que en gran medida significan el reconocimiento de la memoria histórica de la nakba palestina, además de resistir los procesos de memoricidio (Ramos, 2015) producidos sobre los territorios colonizados. 


\section{Bibliografía}

ABU-TARBUSH QUEVEDO, José (2009): "El Conflicto Israelo-Palestino Después de Gaza", Anuario CEIPAZ. Crisis y cambio en la sociedad global, no 3, pp.157-180.

ABU-TARBUSH QUEVEDO, José (2013): "Palestina en el Nuevo Contexto Regional: ¿Parálisis o Avances?", Anuario CEIPAZ. El reto de la democracia en un mundo en cambio: respuestas políticas y sociales, $\mathrm{n}$ - 6, pp. 145-162.

ÁLVAREZ-OSSORIO ALVARIÑO, Ignacio (2007): “Hamás 'versus' Al Fatah: dos Gobiernos, ningún Estado", Estudios de Política exterior, Vol. 21-119, pp.79-92.

ARAFEH, Nur (2018): "Economía palestina: las alternativas al Protocolo de París", Grupo de Investigación Palestina Soberana, 9 de abril de 2018, disponible en: http://palestinasoberana.info/?p=20959, [consulta: 2 de mayo de 2018].

ARAFEH, Nur (2017): "50 Years of Occupation: Ongoing Colonial Economic Domination", Al Shabaka, 31 de mayo de 2017, disponible en: https://al-shabaka.org/op-eds/50-years-occupationongoing-colonial-economic-domination/, [consulta: 20 de marzo de 2018].

BARREÑADA BAJO, Isaías (2008): "Palestina 1993-2007: negociaciones, ocupación y anexionismo unilateral" en NÚÑEZ VILLAVERDE, Jesús A; HAGERAATS, Balder y BARREÑADA BAJO, Isaías, Gestión de conflictos en el ámbito internacional: aportaciones para una cultura de paz, Madrid, CIDEAL.

BASALLOTE MARÍN, Antonio; CHECA HIDALGO, Diego; LÓPEZ ARIAS, Lucía: RAMOS TOLOSA, Jorge (2017): Existir es Resistir. Pasado y presente de Palestina-Israel, Granada, Comares.

BOURIS, Dimitris (2012): “The European Union's role in the Palestinian Territories: state-building through Security Sector Reform?", European Security, Vol. 21, no 2, pp. 257-271. https://doi.org/10.1080/09662839.2012.665804

BOUTROS Boutros-Ghali (1992): Un Programa de Paz. Nueva York, ONU.

BUSBRIDGE, Rachel (2017): “Israel-Palestine and the Settler Colonial 'Turn': From Interpretation to Decolonization", Theory, Culture \& Society, Vol. 0, no 0, pp. 1-25. http://dx.doi.org/10.1177/0263276416688544

CHANDLER, David (2010): International Statebuilding: the rise of post-liberal governance. Critical issues in global politics, Oxon, Nueva York, Routledge. http://dx.doi.org/10.4324/9780203847329

CHOWDHRY, Gaeta, y NAIR, Sheila (2002): "Introduction: power in a postcolonial world: race, gender, and class in international relations" en CHOWDHRY, Geeta y NAIR, Sheila (eds.): Power, postcolonialism, and international relations: reading race, Gender, and class, Londres, Nueva York, Routledge, pp.1-32. http://dx.doi.org/10.4324/9781315017181

CISCH (2009): ¿'Ocupación, Colonialismo, Apartheid? Reevaluación de las prácticas de Israel en los Territorios Ocupados Palestinos bajo la legislación internacional, Ciudad del Cabo, Consejo Investigador de Sudáfrica para las Ciencias Humanas.

COLLINS, John (2011): "Más allá del "conflicto": Palestina y las estructuras profundas de la colonización global", Política y Sociedad, Vol. 48, no 1, pp. 139-154.

COMISIÓN EUROPEA (2014): Implementation of the European Neighbourhood Policy in Palestine Progress in 2013 and recommendations for action. Joint Staff Working Document, High Representative of the European Union for Foreign Affairs and Security Policy, 27 de marzo de 2014, Bruselas.

DANA, Tariq (2014): "Esos capitalistas palestinos que han ido demasiado lejos", Viento Sur, 13 de marzo de 2014, disponible en: http://vientosur.info/spip.php?article8846\#sthash.CG41ERSN.dpuf, [consulta: 20 de septiembre de 2016]. 
DE JONG, Anne (2017): "Zionist hegemony, the settler colonial conquest of Palestine and the problem with conflict: a critical genealogy of the notion of binary conflict", Settler Colonial Studies, pp. 1-20. https://doi.org/10.1080/2201473X.2017.1321171

DE SOUSA SANTOS, Boaventura y MENESES, Maria Paula (eds.) (2014): Epistemologías del Sur. Perspectivas, Madrid, Akal.

DEL ARENAL, Celestino (2014): Etnocentrismo y Teoría de las Relaciones Internacionales: una visión crítica, Madrid, Editorial Tecnos.

DOYLE, Michael W. (diciembre de 1986): "Liberalism and World Politics", The American Political Science Review, Vol. 80-4, pp. 1151-1169. https://doi.org/10.1017/S0003055400185041

DUFFIELD, Mark (2004): Las nuevas guerras en el mundo global. La convergencia entre desarrollo y seguridad, Madrid, Editorial Akal.

ESCWA (2017): Economic trends and impacts: foreign aid and development in the Arab region, Issue no 4, Nueva York, ONU.

FARSAKH, Leila (2008): "The Political Economy of Israeli Occupation: What is Colonial about It?", Electronic Journal of Middle Eastern Studies, no 8.

FONSECA, Melody, Jerrems, Ari (febrero de 2012): "Pensamiento decolonial: ¿una "nueva" apuesta en las Relaciones Internacionales?", Relaciones Internacionales, GERI - UAM, № 19, pp. 103-121.

FRIEDRICH, Roland y LUETHOLD Arnold (2007): Entry-Points to Palestinian Security Sector Reform, Geneva Centre for the Democratic Control of Armed Forces, pp. 145-156.

GALINDO RODRIGUEZ, Fernando (febrero-mayo de 2013): "Enfoques postcoloniales en Relaciones Internacionales: un breve recorrido por sus debates y sus desarrollos teóricos", Relaciones Internacionales, GERI - UAM, no22, pp. 85-107.

GELARDO, Teresa (2010): La Tesis de la Paz Democrática y el Uso de la Fuerza. Discusión sobre el Supuesto Liberal en la Legitimación de las Intervenciones Internacionales, Tesis Doctoral, Universidad Pública de Navarra, pp. 172-173.

GOLAN, Arnon (2001): "European Imperialism and the Development of Modern Palestine: Was Zionism a Form of Colonialism?", Space and Polity, Vol. 5, no 2, pp. 127-143. https://doi.org/10.1080/13562570120104445

HILAL, Jamil (2015): "Rethinking Palestine: settler-colonialism, neoliberalism and individualism in the West Bank and Gaza Strip", Contemporary Arab Affairs, Vol. 8, no 3, pp. 351-362. http://dx.doi.org/10.1080/17550912.2015.1052226

IKV PAX CHRISTI (2012): Analysing israel's economic policy towards Palestine and the practical implications of Netanyahu's economic peace, Commissioned Research Paper, Utrecht, IKV Pax Christi.

JABARY SALAMANCA, Omar, et al. (2012): "Past is present: Settler colonialism in Palestine", Settler Colonial Studies, Vol. 2, no 1, pp. 1-8. https://doi.org/10.1080/2201473X.2012.10648823

JABRI, Vivienne (2013): "Peacebuilding, the local and the international: a colonial or a postcolonial rationality?", Peacebuilding, Vol. 1, no 1, Londres, Nueva York, Routledge, pp. 3-16. http://dx.doi.org/10.1080/21647259.2013.756253

KANT, Inmanuel (2005): Sobre la paz perpetua, Madrid, Tecnos.

KHALIDI, Rashid (2003): "Palestina: ¿'Hoja de Ruta' o Ruta Hacia la Muerte?", The Nation, 22 de mayo de 2003, disponible en: http://www.rebelion.org/hemeroteca/palestina/030528khalidi.htm, [consulta: 5 de agosto de 2016]. 
KHALIDI, Raja y SAMOUR Sobhi (2011): “Neoliberalism as Liberation: The Statehood Program and the Remaking of the Palestinian National Movement", Journal of Palestine Studies, Vol. 40-2, pp. 625. https://dx.doi.org/10.1525/ips.2011.XL.2.6

KHAN, Mustafa H. (2004): "Evaluating the emerging Palestinian state: 'good governance' versus 'transformation potential", en KHAN, Mustafa H. (ed.): State formation in Palestine viability and governance during a social transformation, Londres, The Routledge Curzon Political Economy of the Middle East and North Africa Series, pp. 13-63.

KREBS, Mike y OLWAN, Dana M. (2012): "From Jerusalem to the Grand River, our struggles are one: challenging Canadian and Israeli settler colonialism", Settler Colonial Studies, Vol. 2, no 2, pp. 138-164. http://dx.doi.org/10.1080/2201473X.2012.10648846

LEECH, Philip (2012): Re-reading the Myth of Fayyadism: A Critical Analysis of the Palestinian Authority's Reform and State-building Agenda, 2008-2011, Doha, Arab Center for Research and Policy Studies.

LIDÉN, Kristoffer (2011): “Peace, self-governance and international engagement: from neo-colonial to postcolonial peacebuilding", en TADJBAKHSH Shahrbanou (ed.): Rethinking the liberal peace: external models and local alternatives, Oxon, Nueva York, Routledge, pp. 57-74. http://dx.doi.org/10.13140/RG.2.1.1575.1521

MAC GINTY, Roger (2011): International peacebuilding and local resistance. Hybrid forms of peace, Nueva York, Palgrave Macmillan.

MASALHA, Nur (2012): Nakba. Limpieza étnica, lucha por la historia. Barcelona: Bellaterra.

NAGARAJAN, Nithya (2014): "Development under Colonialism?", en TABAR, Linda y JABARY, Omar, et al., Critical readings of development under colonialism: Towards a political economy for liberation in the Occupied Palestinian Territories, Ramala, Birzeit University's Center for Development Studies, pp. 67-86.

NASHASHIBI, Karim (2007): "Palestinian Finance under Siege: Economic Decline and Institutional Degradation", A Year of Decline: The Financial and Institutional Status of the Palestinian Authority, OCHA Special Focus.

NEWMAN, Edwar; PARIS, Roland y RICHMOND, Oliver P. (2009): New perspectives on liberal peacebuildig, Nueva York, Tokio, París, United Nations University Press.

NITZAN, Jonathan y BICHLER, Shimshon (1996): "From war profits to peace dividends: the new political economy of Israel", Capital \& Class, no 60, pp. 61-94.

NITZAN, Jonathan y BICHLER, Shimshon (2002): The Global Political Economy of Israel, Londres, Editorial Pluto Press.

PAFFENHOLZ, Thania y CHRISTOPH Spurk (2006): "Civil society, civic engagement and peacebuilding", Social Development Papers, Conflict Prevention and Reconstruction, Paper no 36, Washington, D.C, Banco Mundial.

PAPPÉ, Ilan (2008): "Zionism as colonialism: A comparative view of diluted colonialism in Asia and Africa", South Atlantic Quarterly, Vol. 107, no 4, pp. 611-633. http://dx.doi.org/10.1215/003828762008-009

PAPPÉ, Ilan (2014): La idea de Israel. Una historia de poder y conocimiento, Madrid, Akal.

PARIS, Roland (1997): "Peacebuilding and the limits of liberal internationalism", International Security, Vol. 22, no 2, pp. 54-89. http://dx.doi.org/10.2307/2539367

PARIS, Roland (2002): "International peacebuilding and the mission 'civilisatrice", Review of International Studies, no 28, 637-656, (2002). DOI: https://doi.org/10.1017/S026021050200637X PELED, Yoav (2004): “¿Beneficios o gloria? El vigésimo octavo día de Elul de Arik Sharon”, New Left Review, no 29, pp. 45-67.

PERES, Shimon (1993): Oriente Medio. Año Cero, Barcelona, Grijalbo. 
PITERBERG, Gabriel (primavera de 2015): "Israeli Sociology's young Hegelian Gershon Shafir and the settler-colonial framework", Journal of Palestine Studies, Vol. 44, no 3, pp. 17-38, DOI: 10.1525/jps.2015.44.3.17

QUIJANO, Aníbal (2000): "Colonialidad del poder, eurocentrismo y América Latina" en LANDER, Edgardo (comp.) La colonialidad del saber: eurocentrismo y ciencias sociales. Perspectivas Latinoamericanas, Buenos Aires, CLACSO, pp. 201-245.

RAJAGOPAL, Balakrishnan (2005): El derecho internacional desde abajo. El desarrollo, los movimientos sociales y la resistencia del tercer sector, Bogotá, Colección en clave de Sur.

RAMOS TOLOSA, Jorge (2015): “¿No hay eco en el eco?». El memoricidio de la Nakba y sus resistencias", Revista de Estudios Internacionales Mediterráneos (REIM), no 18, pp: 164-186.

REINHART, Tanya y AHRONOTH, Yedioth (2003): "The guaranteed failure of the Road Map", The Electronic Intifada, 15 de mayo, disponible en: https://electronicintifada.net/content/guaranteedfailure-road-map/4583

RICHMOND, Oliver P. (2006): "The problem of peace: understanding the 'liberal peace'", Conflict, Security \& Development, Vol. 6-3, pp. 291-314. http://dx.doi.org/10.1080/14678800600933480

RICHMOND, Oliver P. (2011): "Resistencia y paz postliberal”, Relaciones Internacionales, GERI UAM, no 16, pp. 13-46.

RODINSON, Maxime (1973): Israel: A Colonial Settler State?, Nueva York, Monad Press.

SABARATMAN, Meera (2011): "IR in dialogue... but can we change the subjects? A typology of decolonising strategies for the study of world politics", Millennium: Journal of International Studies, Vol. 39, no 3, pp.781-803. http://dx.doi.org/10.1177/0305829811404270

SALOMÓN GONZÁLEZ, Mónica (2002): “La teoría de las Relaciones Internacionales en los albores del siglo XXI: diálogo, disidencia, aproximaciones", Revista CIDOB d'Afers Internacionals, no 56, pp. 7-52.

SAMARA, Adel (2000): "Globalization, the Palestinian economy, and the 'peace process'", Journal of Palestine Studies, Vol. 29, no 2-114, pp. 20-34. http://dx.doi.org/10.2307/2676534

SAYEGH, Fayez, A. (1965): Zionist colonialism in Palestine, Research Center, Beirut, Palestine Liberation Organization.

SAYIGH, Yezid y SHIKAKI, Khalil (1999): Strengthening Palestinian Public Institutions, Independent Task Force sponsored by the Council on Foreign Relations, The Rocard Report, Nueva York, UN: U.S./Middle East Project.

SETH, Sanjay, (2011): "Postcolonial theory and the critique of international relations", Millennium Journal of International Studies, Vol. 40-1, pp. 167-183. http://dx.doi.org/10.1177/0305829811412325

SHAFIR, Gershon (1989): Land, labor and the origins of the Israeli Palestinian conflict, 1882-1914. Cambridge, Cambridge University Press.

SHLAIM, Avi (2005): "The rise and fall of the Oslo process", en FAWCETT, Louise (ed.): International relations of the Middle East, Oxford: Oxford University Press, pp. 241-261.

TABAR, Linda y DESAI, Chandni (2017): "Decolonization is a global project: From Palestine to the Americas", Decolonization: Indigeneity, Education \& Society, Vol. 6, no 1, pp. i-xix.

TADJBAKHSH, Shahrbanou (ed.) (2011): Rethinking the liberal peace: external models and local alternatives, Milton Park, Routledge.

TARTIR, Alaa (2015): "Securitised development and Palestinian authoritarianism under Fayyadism", Conflict, Security \& Development, Vol. 15, no 5, pp. 479-502. https://doi.org/10.1080/14678802.2015.1100016 
TARTIR, Alaa (diciembre de 2015): "Palestine-Israel: decolonization now, peace later",

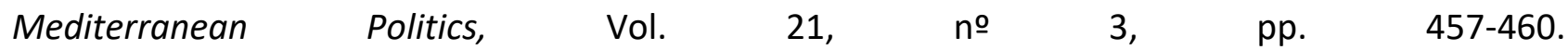
http://dx.doi.org/10.1080/13629395.2015.1126391

TILLEY, Virginia (2012): Beyond occupation: Apartheid, colonialism and international law in the Occupied Palestinian Territories, Londres, Pluto Press.

TURNER, Mandy (noviembre de 2012): "Completing the circle: peacebuilding as colonial practice in the Occupied Palestinian Territory", International Peacekeeping, vol 19, no 5, pp. 492-507. http://dx.doi.org/10.1080/13533312.2012.709774

TURNER, Mandy (2013): "Statebuilding in Palestine. Caught between occupation, realpolitik, and the liberal peace", en CHANDLER, David y SISK, Timothy D. (eds.): Routledge handbook of international statebuilding, Nueva York, Routledge, pp. 339-349.

TURNER, Mandy (2015): "The political economy of western aid in the Occupied Palestinian Territory since 1993", en: TURNER, Mandy y SHWEIKI, Omar (eds.): Decolonizing Palestinian political economy: de-development and beyond, Nueva York, Palgrave Macmillan, pp. 32-52.

UNCTAD/GDS/APP (2006): The Palestinian war-torn economy: aid, development and State formation, Nueva York, ONU.

VERACINI, Lorenzo (2013): "The other shift: settler colonialism, Israel, and the occupation", Journal of Palestine Studies, no 42. pp. 26-42. http://dx.doi.org/10.1525/ips.2013.42.2.26

WOLFE, Patrick (2006): "Settler colonialism and the elimination of the native", Journal of Genocide Research, Vol. 8, no 4, pp. 387-409. http://dx.doi.org/10.1080/14623520601056240 